\title{
A Novel Splash Plate Design for Serial Reuse Raceways
}

\author{
Michael E. Barnes, Eric Krebs, Patrick A. Nero, Kelby Torgerson, Daniel V. Johnson
}

McNenny State Fish Hatchery, South Dakota Department of Game, Fish \& Parks, Spearfish, SD, USA

Email:mike.barnes@state.sd.us

How to cite this paper: Barnes, M.E., Krebs, E., Nero, P.A., Torgerson, K. and Johnson, D.V. (2017) A Novel Splash Plate Design for Serial Reuse Raceways. World Journal of Engineering and Technology, 5, 21-26.

https://doi.org/10.4236/wjet.2017.51003

Received: November 15, 2016 Accepted: December 31, 2016

Published: January 3, 2017

Copyright $\odot 2017$ by authors and Scientific Research Publishing Inc. This work is licensed under the Creative Commons Attribution International License (CC BY 4.0).

http://creativecommons.org/licenses/by/4.0/

\begin{abstract}
Serial reuse raceways in fish hatcheries typically use dam boards and screens to separate each raceway unit in the series. This paper describes a novel raceway splash plate constructed of aluminum plate and angle, which eliminates the need for screens when mounted on top of raceway dam boards. In addition to reducing the labor required to remove and replace, and clean screens, the splash plate increased the amount of available rearing space. Incoming water dissolved oxygen concentrations were also increased. These splash plates are relatively easy and inexpensive to fabricate, and their use can lead to increased efficiencies during hatchery rearing.
\end{abstract}

\section{Keywords}

Aquaculture, Raceways, Splash Plate, Serial Reuse

\section{Introduction}

Serial reuse raceways are sequential rectangular rearing units commonly used during fish rearing, particularly with trout and salmon [1]. Water enters an upper raceway section and is used for fish production before subsequent discharge into a sequentially lower raceway section. After being used for fish production in this lower raceway section, water is discharged for use into another sequentiallylower raceway section, with the process repeated up to ten times [2] [3]. The raceways in the series are typically separated from each other by dam boards or vertical walls [4] [5], with vertical screens placed at the head end of each raceway section to prevent fish from jumping from a lower raceway section into an upper one. There is typically a slight drop in elevation from an upper to lower raceway section, providing some passive aeration as the water drops over the dam boards or overflow weirs [3] [6]. Water quality, and particularly dissolved oxygen levels, decrease in the lower raceway sections [6], and active aeration or supplemental 
oxygen injection can be used [4] [7] [8].

Vertical screens in raceways are susceptible to plugging from aquatic vegetation or airborne debris such as leaves or litter [5], particularly when rearing small fish requiring small screen mesh sizes. Any such plugging of raceway screens restricts water flows, potentially leading to decreased oxygen levels and increased physiological stress, resulting in an increased probability of disease outbreaks and a general decline in fish rearing performance. Restricted raceway water flows due to plugged screens can also rapidly produce large-scale mortality of fish, which are typically held at high densities during production aquaculture. As fish grow, plugging issues can be reduced by increasing screen mesh sizes, although considerable labor may be required to remove and replace screens depending on the number of raceway sections.

In addition to requiring constant vigilance to prevent screen plugging, typical serial raceway designs do not allow aquaculturists to use of all of the available raceway rearing space. The placement of the screens at the head end of the raceway prohibits the fish from accessing the area between the upper screen and the raceway dam boards. In order to use all of the raceway for rearing, eliminate the numerous risks associated with the use of vertical screens, reduce labor requirements, and increase the amount of dissolved oxygen in the rearing water, alternatives to the traditional raceway dam board and screen design are needed.

This paper describes a novel raceway splash plate design which is non-plugging, passively adds atmospheric oxygen to the water, and eliminates the need for vertical screens at the head of each raceway section.

\section{Design and Evaluation}

This splash plate was developed and tested at McNenny State Fish Hatchery, Spearfish, South Dakota. At McNenny Hatchery, eight serial raceways $(91.5 \mathrm{~m}$ long, $2.4 \mathrm{~m}$ wide, $0.76 \mathrm{~m}$ deep) each consisted of three $30.5 \mathrm{~m}$ sections, were historically configured as illustrated in Figure 1(a). Because the new splash plate design allowed for the removal of the upper raceway screen, raceway configuration changed after splash plate installation as illustrated in Figure 1(b). As a result of screen removal, an additional $1.3 \mathrm{~m}^{3}$ of rearing space became available in the two lower sections in each raceway $\left(2.6 \mathrm{~m}^{3}\right.$ added per raceway). With eight raceways at McNenny Hatchery, an additional $20.8 \mathrm{~m}^{3}$ of rearing space was added.

The splash plates were constructed from $0.635 \mathrm{~cm}$ thick aluminum sheeting. Each splash plate consists of a $30.5 \mathrm{~cm} \times 243 \mathrm{~cm}$ back plate secured to the terminal raceway dam boards by four pieces of $5.08 \mathrm{~cm}$ aluminum angle $21.6 \mathrm{~cm}$ long (Figures 2-4). On top of the aluminum angle are three $2.54 \mathrm{~cm} \times 243 \mathrm{~cm}$ aluminum strips spaced $0.95 \mathrm{~cm}$ apart. The back plate is welded to the four aluminum angle pieces at exactly $42.5^{\circ}$ (Figure 5). Test angles of greater or less than $42.5^{\circ}$ resulted in trout either swimming under, or jumping over, the splash plate to gain access to the waste collection area of the upper raceway.

The splash plates were evaluated during hatchery operations with multiple 


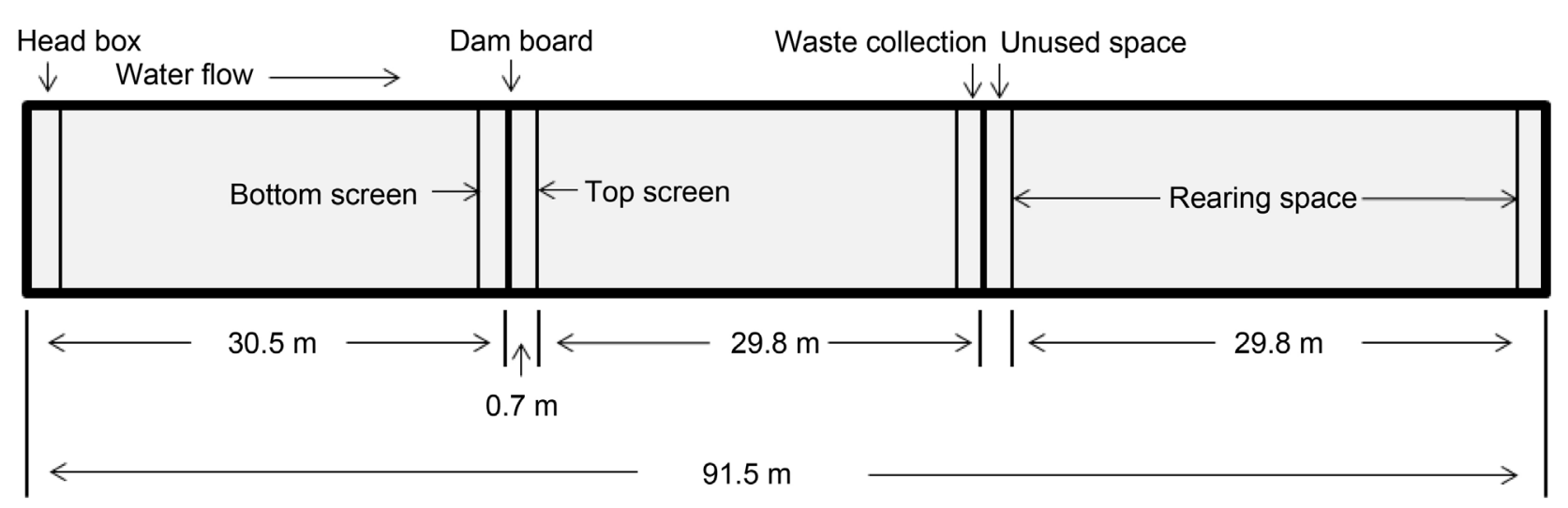

(a)

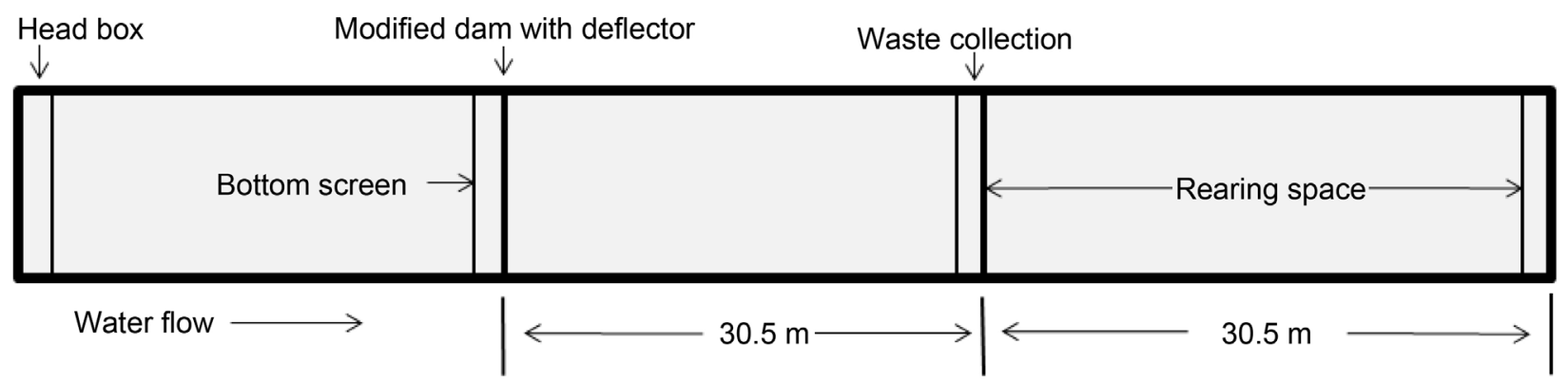

(b)

Figure 1. (a) Original configuration of a serial reuse raceway at McNenny Hatchery. (b) Configuration of a serial reuse raceway after splash plate installation.

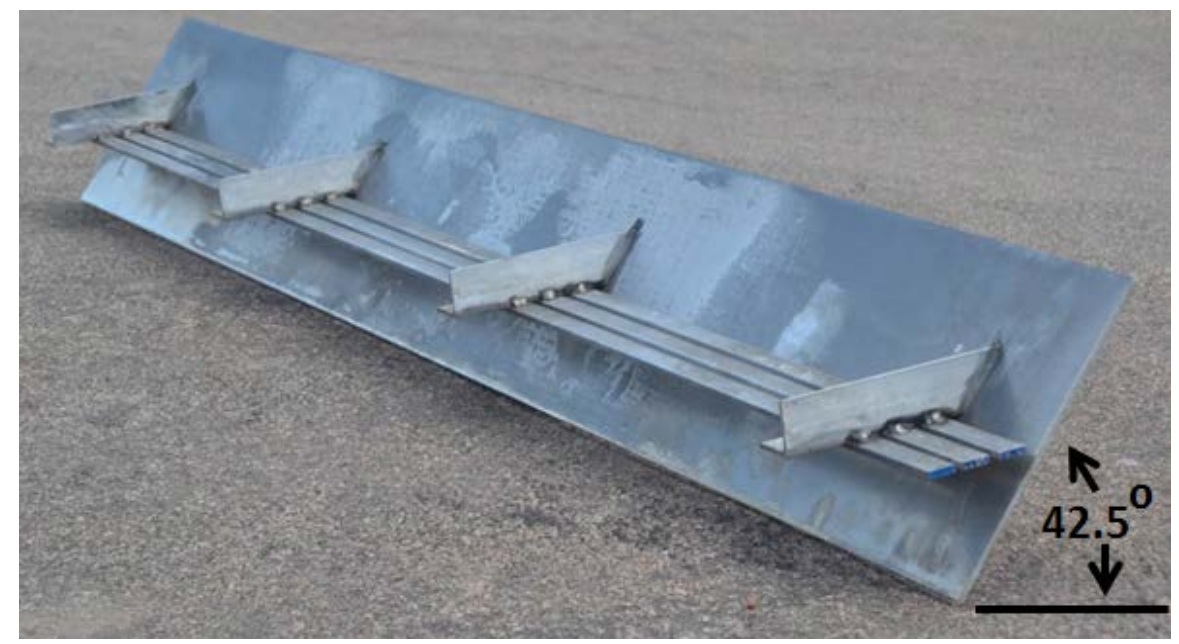

Figure 2. Image of a splash plate prior to raceway installation.

rainbow trout Oncorhynchus mykiss and brown trout Salmo trutta strains, at fish sizes ranging from 30 to $2000 \mathrm{~g}$, and under raceway water inflows ranging from 600 to $2000 \mathrm{~L} / \mathrm{min}$. No fish movement from a lower to higher raceway section was observed. In addition, the use of these splash plates increased dissolved oxygen levels in the incoming water up to nearly $1.8 \mathrm{mg} / \mathrm{L}$, which was dependent on oxygen levels at the end of the upper raceway section (Figure 6) and raceway water flows [3] (Figure 7). The increases in dissolved oxygen after the water 


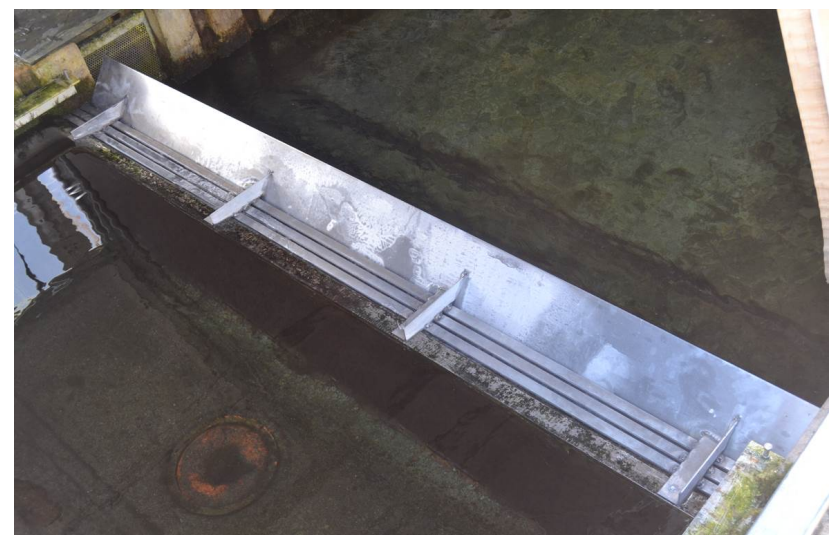

Figure 3. Image of a splash plate installed on a raceway section.
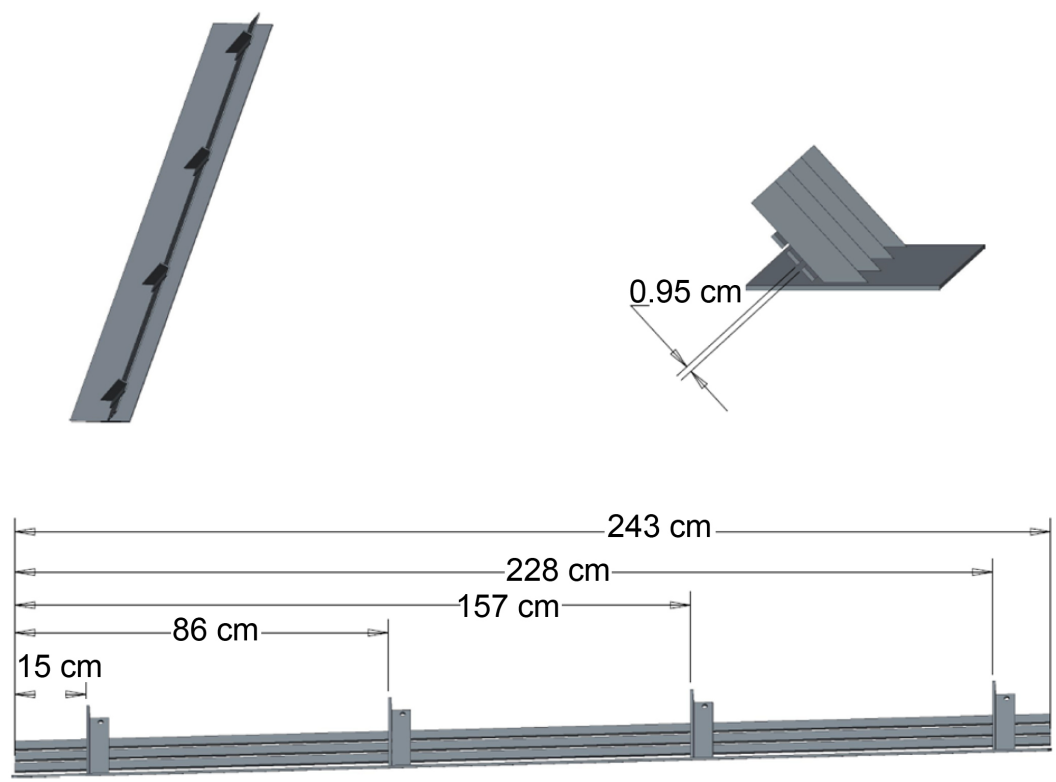

Figure 4. Splash plate schematic.
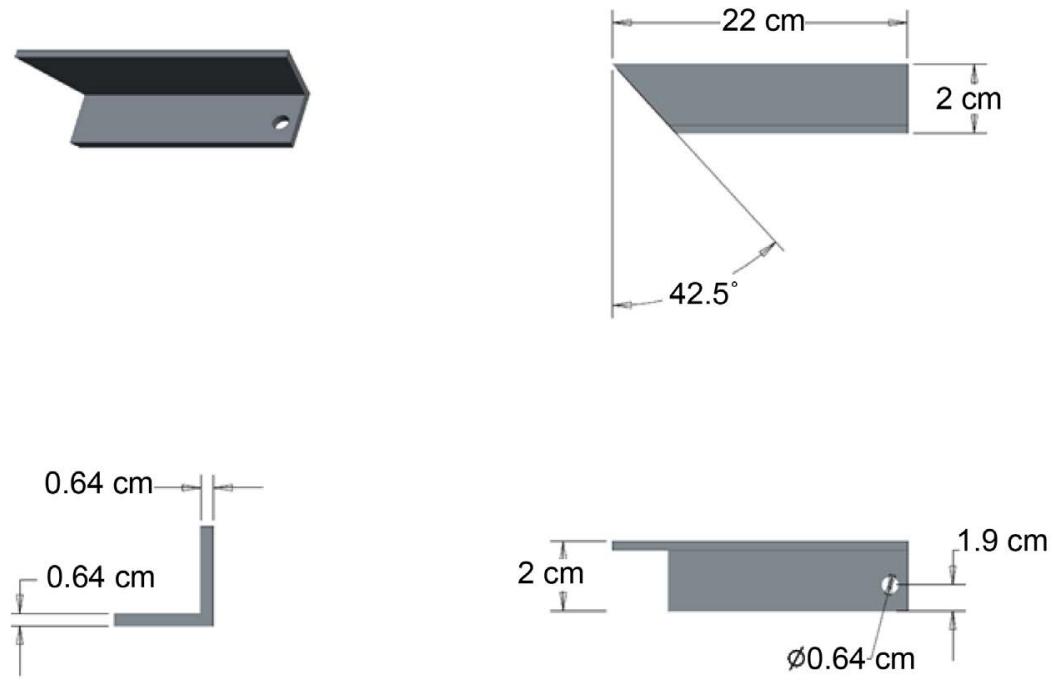

Figure 5. Schematic of angle pieces used to secure the splash plate to a raceway dam board. 


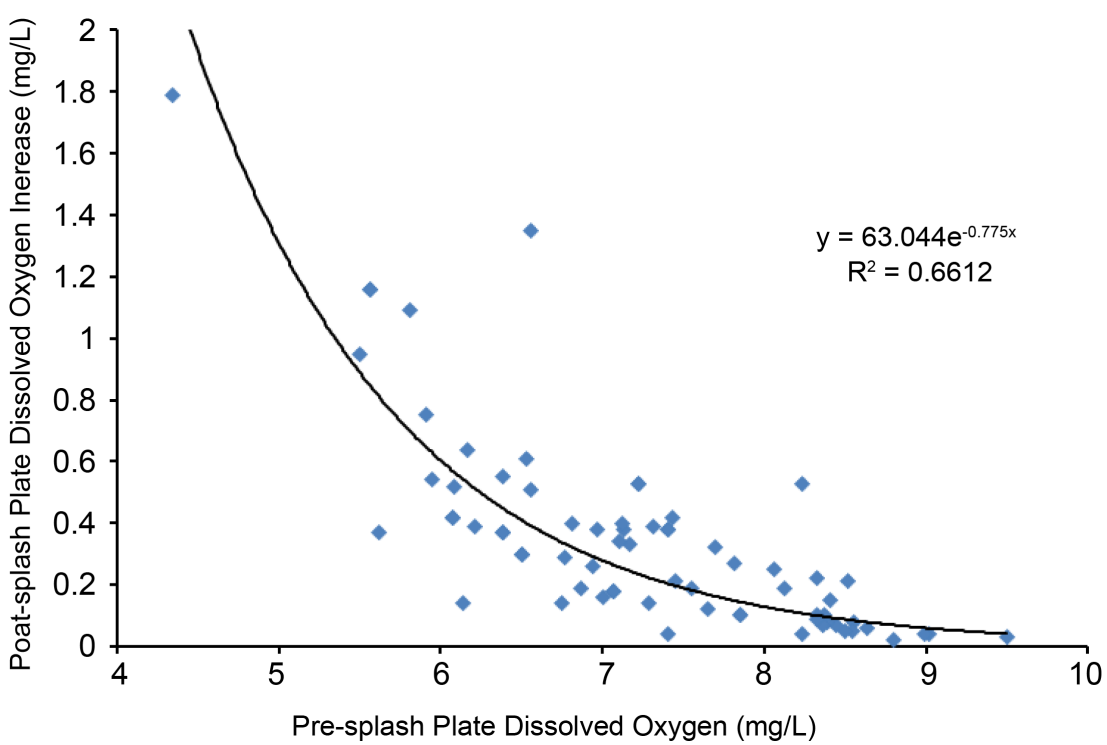

Figure 6. Changes in post-splash plate dissolved oxygen levels in relation to dissolved oxygen levels in the incoming (pre-splash plate) water.

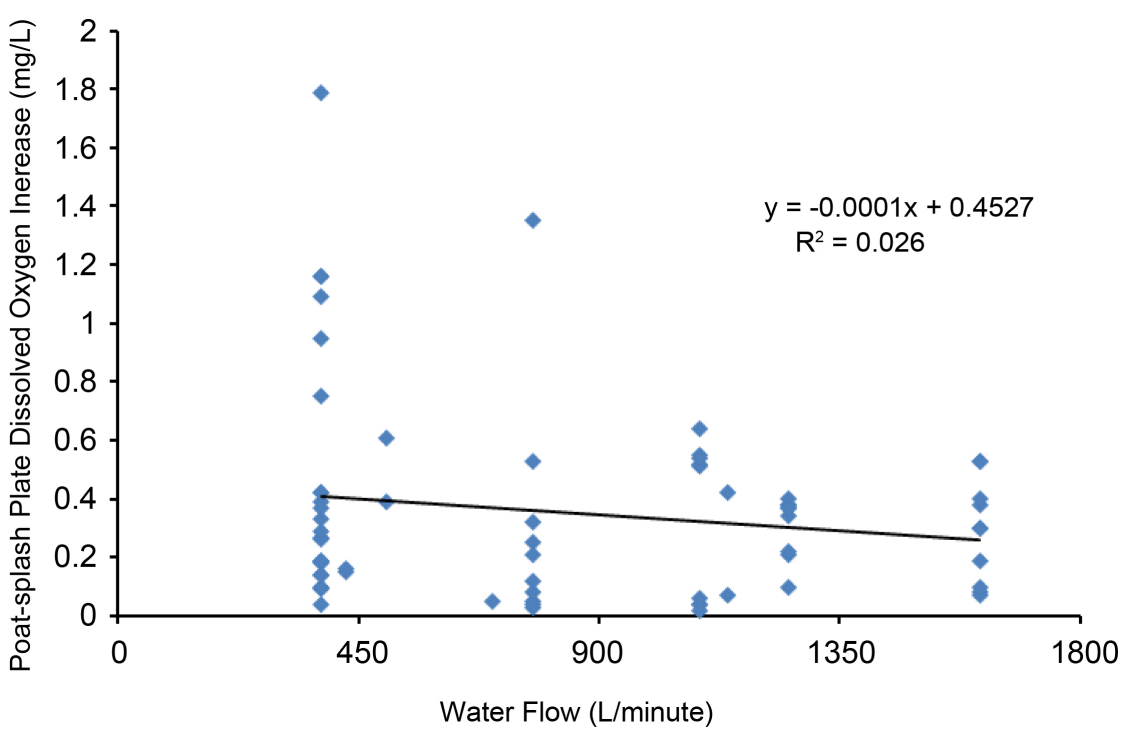

Figure 7. Changes in post-splash plate dissolved oxygen levels in relation to water flow rates.

flowed over the splash plates was similar to that observed in serial reuse raceways using triangular notch weirs, and greater than the increases observed during the use of sharp crested weirs [3].

\section{Conclusion}

The use of the splash plate is highly advantageous and an improvement over typical designs. Labor is reduced because screens to not have to be monitored and cleaned. In addition, the need to change screen sizes in relation to fish sizes is eliminated, not only reducing labor, but also decreasing the numbers and sizes of screens in inventory. The large risk to fish health of having screens plugged is 
also eliminated. Lastly, dissolved oxygen levels and the amount of available raceway rearing space are increased in comparison to traditional serial raceway designs.

\section{Acknowledgements}

We thank Michael Hilmes, Andrew Doyle, Jesse Willis, and Tim Parker for their assistance with this project.

\section{References}

[1] Hinshaw, J.M. and Fornsell, G. (2002) Effluents from Raceways. In: Tomasso, J.R., Ed., Aquaculture and the Environment in the United States, US Aquaculture Society, Baton Rouge, Louisiana, 77-103.

[2] Piper, R.G., McElwain, I.B., Orme L.E., McCraren J.P., Fowler L.G., et al. (1982) Fish Hatchery Management. US Fish and Wildlife Service, Washington DC.

[3] Colt, J., Watten, B. and Rust, M. (2009) Modeling Carbon Dioxide, pH, and UnIonized Ammonia Relationships in Serial Reuse Systems. Aquacultural Engineering, 40, 28-44. https://doi.org/10.1016/j.aquaeng.2008.10.004

[4] Davenport, M.T., Timmons, M.B., Vinci, B.J. and Crum, M.K. (2001) Experimental Evaluation of Low Head Oxygenators. Aquacultural Engineering, 24, 245-256. https://doi.org/10.1016/s0144-8609(01)00065-6

[5] Fizer, E., Gray, D.D. and Semmens, K.J. (2013) Effects of Screens on the Turbulent Flow in the Quiescent Zone of a Rectangular Aquaculture Raceway. Aquaculture Engineering, 57, 48-53. https://doi.org/10.1016/j.aquaeng.2013.07.001

[6] Summerfelt, S.T., Davidson, J.W., Waldrop, T.B., Tsukuda, S.M. and Bebak-Williams, J. (2004) A Partial-Reuse System for Coldwater Aquaculture. Aquacultural Engineering, 31, 157-181. https://doi.org/10.1016/j.aquaeng.2004.03.005

[7] Leitritz, E. and Lewis, R.C. (1976) Trout and Salmon Culture (Hatchery Methods). California Department of Fish and Game Fish Bulletin 164.

[8] Colt, J. and Orwicz, K. (1991) Modeling Production Capacity of Aquatic Culture Systems under Freshwater Conditions. Aquacultural Engineering, 10, 1-29. https://doi.org/10.1016/0144-8609(91)90008-8

\section{Submit or recommend next manuscript to SCIRP and we will provide best service for you:}

Accepting pre-submission inquiries through Email, Facebook, LinkedIn, Twitter, etc. A wide selection of journals (inclusive of 9 subjects, more than 200 journals)

Providing 24-hour high-quality service

User-friendly online submission system

Fair and swift peer-review system

Efficient typesetting and proofreading procedure

Display of the result of downloads and visits, as well as the number of cited articles

Maximum dissemination of your research work

Submit your manuscript at: http://papersubmission.scirp.org/

Or contactwjet@scirp.org 